\title{
EFFECT OF VARIOUS PROCESS PARAMETERS ON FRICTION STIR WELDED JOINT: A REVIEW
}

\author{
Shrikant G.Dalu' ${ }^{1}$ M. T. Shete \\ ${ }^{1}$ M.Tech. student, Production Engineering, Govt. College of Engineering, Amravati, (M.S.) India. \\ ${ }^{2}$ Asst. Professor, Mechanical Engineering Department, Govt. College of Engineering, Amravati, (M.S.),India \\ dalushrikant1@gmail.com,mtshete@yahoo.com
}

\begin{abstract}
This paper is a review of research work in the last decade on friction stir welding. Research is going on to investigate the effect of various process parameters on quality of the welded joint. In this study, the investigation is made on the effect of various process parameters, such as tool rotational speed, traverse speed, axial force and tool geometry on the quality of the welded joint are reviewed. Yield strength, ultimate strength, elongation, toughness, microstructure of the joint are evaluated and correlated with received base material. To compare and validate experimental results, FEA model is the best way to study the quality of welded joint.
\end{abstract}

Keywords- Friction stir welding, tool rotation and transverse speed, axial force, tool geometry

\section{INTRODUCTION}

Friction stir welding (FSW) is a material joining process. It is a highly important and recently developed joining technology that produces a solid phase bond. It is particularly appropriate for the welding of high strength alloys. Its main characteristic is to join material without reaching the fusion temperature. It enables to weld almost all types of aluminium alloys, even the one classified as non-weldable by fusion welding due to hot cracking and poor solidification microstructure in the fusion zone. FSW is considered to be the most significant development in metal joining in a decade and is a "green" technology due to its energy efficiency, environment friendliness, and versatility. The key benefits of FSW are summarized in Table 1[1].

Table 1 Key benefits of FSW are summarized below

\begin{tabular}{|c|c|}
\hline Metallurgical benefits & Environmental benefits \\
\hline $\begin{array}{ll}\text { - } & \text { Solid phase process. } \\
\text { - } & \text { Low distortion of } \\
& \text { work piece. } \\
\text { - } & \text { Good dimensional } \\
& \text { stability \& } \\
& \text { repeatability. } \\
\text { - } & \text { No loss of alloying } \\
& \text { elements. } \\
\text { - } & \text { Fine microstructure } \\
\text { - } & \text { Absence of cracking }\end{array}$ & $\begin{array}{ll}\text { - } & \text { No shielding gas } \\
\text { - } & \text { Nequired. } \\
\text { No surface } \\
\text { cleaning } \\
\text { required. } \\
\text { - } \\
\text { Eliminate } \\
\text { grinding wastes. } \\
\text { Consumable } \\
\text { materials saving. }\end{array}$ \\
\hline
\end{tabular}

Friction stir welding process parameters and welded joint are analysed by testing welded joint or modeling welding process using FEA software's and simulating it. The FEA software, such as WELDSOFT, ABACUS, Altair Hyperworks, DEFORM-3D etc. are more user friendly to the designer such that modifications of any data is easily done on seeing preview of the simulated weld conditions. The accuracy of the result depends upon the assumption made in constructing the model. The results obtained from FEA simulation are verified by running a confirmatory experiment [20].

\section{FSW PROCESS}

The working principle of Friction Stir Welding process is shown in Fig. 1 The FSW process utilizes a rotating tool to perform the welding process. The rotating tool consist of small pin (probe) underneath a larger shoulder. The tool serves three primary functions, that is, heating of the workpiece, movement of material to produce the joint, and containment the hot metal beneath the tool shoulder. In FSW, rotating shouldered tool plunges into the joining point of plates and the heat is originally developed from the friction between the welding tool (including the shoulder and the probe) and the welded material, which causes the welded material to soften at a temperature less than its melting point. The tool shoulder restricts softened material underneath the shoulder is further leads to movement of material from the front of the pin to the back of the pin by the rotational and transverse movements of tool. It is expected that this process will inherently produce a weld with less residual stress and distortion as compared to the fusion welding methods, since no melting of the material occurs during the welding [19]. 


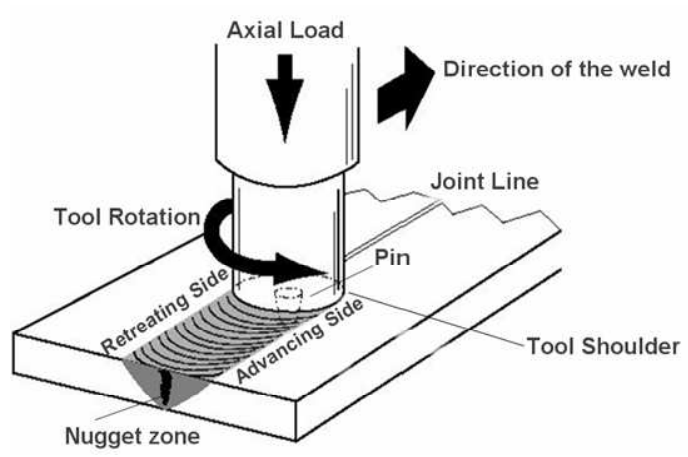

Fig. 1: Schematic of Friction Stir Welding.

\section{WELDING PARAMETERS}

FSW involves complex material movement and plastic deformation. Welding parameters, Tool geometry and joint design exert significant effect on the material flow pattern and temperature distribution, thereby influencing the micro structural evolution of material [1]. Therefore, welding speed, the tool rotational speed, the tilt angle of the tool, tool material and the tool design are the main independent variables that are used to control the FSW process.

\subsection{Tool Rotation}

For FSW, two parameters are very important: tool rotation rate $(\mathrm{v}, \mathrm{rpm})$ in clockwise or counter clockwise direction. The motion of the tool generates frictional heat within the work pieces, extruding the softened plasticized material around it and forging the same in place so as to form a solid-state joint.

\subsection{Transverse Speed}

The welding speed depends on several factors, such as alloy type, rotational speed, penetration depth, and joint type. Higher tool rotation rates generate higher temperature because of higher friction heating and result in more intense stirring and mixing of material. During traversing, softened material from the leading edge moves to the trailing edge due to the tool rotation and the traverse movement of the tool, and this transferred material, are solidify in the trailing edge of the tool by the application of an axial force [1].

\subsection{Tool Tilt Angle}

In addition to the tool rotation rate and traverse speed, another important process parameter is the angle of spindle or tool tilt with respect to the workpiece surface. A suitable tilt of the spindle towards trailing direction ensures that the shoulder of the tool holds the stirred material by threaded pin and move material efficiently from the front to the back of the pin. The tool is usually characterized by a small tilt angle $(\theta)$, and as it is inserted into the sheets, the blanks material undergoes to a local backward extrusion process up to the tool shoulder. Further, the plunge depth of pin into the work pieces (also called target depth) is important for producing sound welds with smooth tool shoulders [1].

\subsection{Tool Design}

In order to determine the optimum tool geometry, the two components of the torque are used for various shoulder diameters. As the shoulder diameter increases, the sticking torque, MT, increases, reaches a maximum and then decreases. This behavior can be examined, which shows that two main factors affect the value of the sticking torque. First, the strength of the material is decreases with increasing temperature due to an increase in the shoulder diameter. Second, the area over which the torque is applied increases with shoulder diameter [2].

A three-dimensional heat transfer and visco-plastic model is used to compute the influence of pin length and diameter on traverse force during FSW. The total traverse force increases significantly with increase in pin length [3].

\section{PARAMETRIC STUDY OF FSW}

Many investigators have performed friction stir welding to study the effect of various parameters on quality of friction stir welded joint.

\subsection{Aluminium}

V. Balasubramanian, et al [4] investigates the effect of welding speed and tool pin profile on friction stir processing zone formation in AA2219 aluminium alloy. They found that the square pin profile tool at a welding speed $45.6 \mathrm{~mm} / \mathrm{min}$, produced mechanically sound and metallurgically defect free welds with maxium tensile strength, higher hardness. Vivekanandan. P, et al [5] study microstructure and hardness of aluminium 6035 and 8011. At the rotating speed 550rpm and welding speed $60 \mathrm{~mm} / \mathrm{min}$, the fine grain are formed at the center of the weld, due to dynamic recrystallization, which result in higher tensile strength of $50 \mathrm{~N} / \mathrm{mm} 2$ with the maximum hardness of $91 \mathrm{HV}$. M. Abbasi Gharacheh, et al [6]found that increase in the ratio of rotational speed / traverse speed results in formation of large weld nugget, because of increase in heat input easier material flow, therefore probability of formation of incomplete root penetration defect is reduced. A. C. S. Kumar, et al [7]focus on optimization of FSW parameters in different conditions of base material and the microstructures of the as-welded condition are compared with the post weld heat treated microstructures welded in annealed and T6 condition. The result show that in annealed condition tool rotation speed $800 \mathrm{rpm}$ and welding speed 10 $\mathrm{mm} / \mathrm{min}$ and $15 \mathrm{~mm} / \mathrm{min}$ are the optimal parameters. The tool rotation speed $1000 \mathrm{rpm}$ and welding speed $10 \mathrm{~mm} / \mathrm{min}$ are the optimal parameters in ' $\mathrm{T} 6$ ' condition. P. Cavaliere, et al [8] study mechanical and microstructural properties of AA6082 joints. The material welded with the advancing speed of $115 \mathrm{~mm} / \mathrm{min} \&$ fixed rotating speeds of $1600 \mathrm{rpm}$ exhibited 
the best fatigue properties and the higher fatigue limit. A. Kumar, et al [9] find optimum mechanical properties of $\mathrm{Al}$ 6061-T6 alloy \& Mg AZ31B alloy. The joint fabricated using rotational speed of $1120 \mathrm{rpm}$, a welding speed of $40 \mathrm{~mm} / \mathrm{min}$, taper thread pin profile, shoulder diameter of $18 \mathrm{~mm},(\mathrm{D} / \mathrm{d})=3$ shows higher tensile properties. S. Rajakumar, et al [10] study tensile strength properties of AA7075-T6 joints produced by friction stir welding. They found that the joint fabricated at a tool rotational speed of $1400 \mathrm{rpm}$, welding speed of 60 $\mathrm{mm} / \mathrm{min}$, axial force of $8 \mathrm{kN}$, using the tool with $15 \mathrm{~mm}$ shoulder diameter, $5 \mathrm{~mm}$ pin diameter, $45 \mathrm{HRc}$ tool hardness yielded higher strength properties. Prashant Prakash, et al [11] found that at rotational speed 1400rpm, welding speed 25 $\mathrm{mm} / \mathrm{min} \&$ pin length $5.7 \mathrm{~mm}$ maximum tensile strength obtained is $182 \mathrm{MPa}$, gives $60 \%$ joint efficiency. Dr.Ayad M. Takhakh, et al [12] optimum result gained at $80 \mathrm{~mm} / \mathrm{min}$ weld speed and $1500 \mathrm{rpm}$ rotation speed, the efficiency reaches to $89 \%$ of the ultimate tensile strength of the alloy 3003 H13. P. Bahemmat, et al [13] found that the joint is fabricated by fourflute pin profile at rotational speed of 800rpm have demonstrated $90 \%$ ultimate and yield strength and the tapered screw thread joint fabricated at the rotational speed of 600rpm show 84\% ultimate strength in AA2024 aluminium. Patil H S, et al [14] found that the joint fabricated using taper screw thread pin at welding speed of $70 \mathrm{~mm} / \mathrm{min}$ exhibits superior tensile strength of $92.30 \%$ of base metal ultimate strength and $\%$ elongation of $27.58 \%$ in AA6082-0 aluminium.

\subsection{High Density Polyethylene}

Mustafa Kemal Bilici, et al [15] study the effects of welding parameters on friction stir spot welding of HDPE sheets to analyse the strength of the welds of HDPE sheets by means of experimental techniques. Friction stir spot welding parameters such as the tool rotation speed, tool plunge depth, plunge rate, dwell time \& tool geometry are found to affect significantly the weld strength \& weld nugget formation.Fabrizio Quadrini et al[16] studied Friction stir welding of $3 \mathrm{~mm}$ thick high density polyethylene (HDPE) sheet with single pass. At high rotational speeds, a higher amount of heat. Finally they concluded that welding strength is depends on the optimized temperature value in the range of $132-140^{\circ} \mathrm{C}$. M. K. Bilici investigate the effect of tool geometry on friction stir spot welding of polyethylene sheets. They were obtained biggest tensile strength with threaded tool for $4 \mathrm{~mm}$ thick sheets with $7.5 \mathrm{~mm}$ pin diameter, 15 pin angle, $5.5 \mathrm{~mm}$ pin length, $30 \mathrm{~mm}$ shoulder diameter and 6 shoulder angle, pitch length $0.8 \mathrm{~mm}$ [17]. Amir Mostafapour et al They conclude that by utilizing heat assisted friction stir welding, polyethylene sheets could be joined with ultimate tensile strength of higher than $95 \%$ of base material strength at welding speed of $25 \mathrm{~mm} / \mathrm{mim}$ [18].

\section{THERMAL EFFECTS ON FSW}

Many researchers have developed friction stir welding model in various analysis software for analyzing the thermal effect produced in the FSW.C.M. Chen, et al [19] study the thermal history \& thermomechanical process using 3D FEA model. Prediction \& measurement shows that maximum temperature in longitudinal \& lateral direction are beyond shoulder edge. Longitudinal residual stress is greater than lateral residual stress. Binnur Gören Kiral et al [20] found that maximum temperature increases as tool holding time \& rotational speed increases. Temperature decreases as welding speed increases in aluminum alloys Al6061. Muhsin J. J, et al [21] found that the maximum temperature measured during FSW at mid position $629 \mathrm{~K} \&$ numerically value from the simulation is $642 \mathrm{~K}$, which is significantly less than the melting temperature of 7020-T53 aluminum alloy at 916K. Numerical results $(\operatorname{Tmax}=642 \mathrm{~K})$ agreement with measured data $(\mathrm{Tmax}=$ $629 \mathrm{~K}$ ) in 5mm workpiece(AA 7020-T53) thickness. Abdul Arif, et al [22] with dissimilar alloys (AA5086 \& AA6061) they found that longitudinal residual stresses are about 30$45 \%$ transverse of the residual stresses. Values of temperature $\&$ residual stresses by FEM are close to real temperature distribution \& residual stresse in weld construction. N. Rajamanickam, et al [23]study the numerical simulation of thermal history \& residual stresses in friction stir welding of Al 2014-T6. Difference of maximum temperature at same location is less than $120 \mathrm{~K}$ ( $2 \%$ error). Selvamani S.T, et al [24]model is developed to study the temperature analysis of tool geometry \& material properties. Rotational speed \& axial force is constant $\& 0.75 \mathrm{~mm} / \mathrm{sec}$ welding speed yield strength, ultimate strength, elongation \& hardness test of Al6061 alloy is more reliable on retreating side.

\section{CONCLUSIONS}

From the above review it is observed that -

- Tool rotation speed, traverse speed, axial force and tool design are the most significant process parameters in friction stir welding.

- Modeling of friction stir welded joint can be done with various FEA software's such as WELDSOFT, ABACUS, Altair Hyperworks, DEFORM-3D etc.

- Values of temperature and residual stresses by finite element modeling are close to real temperature distribution and residual stresses in experimental construction of friction stir welding.

- Yield strength, ultimate strength, elongation and hardness test are more reliable in both experimental and proposed model.

\section{REFERENCES}

[1]. R.S. Mishra, Z.Y. Ma, "Friction stir welding and processing", Materials Science and Engineering, Vol.50, 2005, pp. 1-78.

[2]. A. Arora , M. Mehta, A. De, T. DebRoy, "Load bearing capacity of tool pin during friction stir welding", Int J Adv Manuf Technol, Vol.61, 2012, 911-920. 
[3]. M. MEHTA, A. ARORA, A. DE, T. DEBROY, "Tool Geometry for Friction Stir Welding-Optimum Shoulder Diameter", The Minerals, Metals \& Materials Society and ASM International, Vol. 42A, 2011, pp.2716-2722.

[4]. K. Elangovan, V. Balasubramanian,"Influences of tool pin profile and welding speed on the formation of friction stir processing zone in AA2219 aluminium alloy", journal of materials processing technology, Vol. 200, 2008 ,pp 163-175.

[5]. Vivekanandan. P1, Arunachalam. V. P, Prakash. T, Savadamuthu. L, " The experimental analysis of friction stir welding on aluminium composites", International Journal of Metallurgical Engineering, Vol.1(4), 2012, pp. 60-65.

[6]. M. Abbasi Gharacheh, A.H. Kokabi, G.H. Daneshi, B. Shalchi, R. Sarrafi, "The influence of the ratio of "rotational speed/traverse speed" $(\omega / \mathrm{v})$ on mechanical properties of AZ31 friction stir welds" International Journal of Machine Tools \& Manufacture, Vol 46, 2006, pp.1983-1987.

[7]. A. C. S. Kumar, Indira Rani M., Marpu R. N, “A study of process parameters of friction stir welded AA 6061 aluminum alloy in o and T6 conditions", ARPN Journal of Engineering and Applied Sciences, VOL. 6, NO. 2, Feb 2011.

[8] P. Cavaliere, A. Squillace, F. Panella, "Effect of welding parameters on mechanical and microstructural properties of AA6082 joints produced by friction stir welding", journal of materials processing technology, journal of materials processing technology, Vol.200, 2008, pp.364-372.

[9]. A.Kumar, S.Ugender, A. Somi Reddy, A. Devaraju, "Influence of process parameters on mechanical properties of friction stir welded aa 6061-T6 alloy and Mg AZ31B alloy", International Journal of Applied Research in Mechanical Engineering (IJARME) ISSN, Vol.3,2013,pp. 2231 -5950.

[10]. S. Rajakumar, C. Muralidharan, V. Balasubramanian, "Influence of friction stir welding process and tool parameters on strength properties of AA7075-T6 aluminium alloy joints" Materials and Design, 2010.[11] Prashant Prakash, Sanjay Kumar Jha, Shree Prakash Lal, "a study of process parameters on friction stir welded AA 6061 aluminium alloy", international journal of innovative research in science, engineering and technology Vol. 2, 2013, pp.2304-2309.

[12]. Dr.Ayad M. Takhakh, Asmaa M. Abdullah, "The Optimization Conditions of Friction Stir Welding (FSW) for Different Rotational and Weld speeds", Nahrain University, College of Engineering Jou rnal (NUCEJ), Vol.15 No.2, 2012, pp. $187-196$.

[13]. P.Bahemmat, A.Rahbari, M.Haghpanahi, M.K.Besharati, "Experimental study on the effect of rotational speed and tool pin profile on aa2024 aluminium friction stir welded butt joints", Proceedings of ECTC 2008 ASME Early Career Technical Conference, October 3-4, 2008, Miami, Florida, USA.

[14]. Patil H S, S. N. Soman, "Experimental study on the effect of welding speed and tool pin profiles on AA6082-O aluminium friction stir welded butt joints", International Journal of Engineering, Science and Technology, Vol. 2, No. 5, 2010, pp. 268-275.
[15]. Mustafa Kemal Bilici, Ahmet Irfan Yükler, "Influence of tool geometry and process parameters on macrostructure and static strength in friction stir spot welded polyethylene sheets", Materials and Design, Vol.33, 2012, pp.145-152.

[16]. Fabrizio Quadrini, Erica Anna Squeo, Giuseppe Bruno, Alessandro Guglielmotti, "Friction Stir Welding Of Polyethylene Sheets" ISSN, 2009, pp. 1221-4566.

[17]. M. K. Bilici, Ahmet Irfan Yükler, "Influence of tool geometry and process parameters on macrostructure and static strength in friction stir spot welded polyethylene sheets", Materials and Design, Vol.33, 2012, pp.145-152.

[18]. Amir Mostafapour,Ehsan Azarsa, "A study on the role of processing parameters in joining polyethylene sheets via heat assisted friction stir welding: Investigating microstructure, tensile and flexural properties", International Journal of the Physical Sciences, Vol. 7(4), 23 January 2012, pp. 647 - 654. [19]. C.M. Chen, R. Kovacevic, "Finite element modeling of friction stir welding-thermal and thermomechanical analysis", International Journal of Machine Tools \& Manufacture, Vol 43, 2003, pp.1319-1326.

[20]. Binnur Goren Kiral, Mustafa Tabanoglu, H. Tarık Serindag, "Finite Element Modeling of friction stir welding in aluminum alloys joint", mathematical and computational applications, vol. 18, no. 2, 2013, pp.122-131.

[21]. Muhsin J. J., Moneer H. Tolephih, Muhammed A. M, "effect of friction stir welding parameters (rotation and transverse) speed on the transient temperature distribution in friction stir welding of AA 7020-T53", ARPN Journal of Engineering and Applied Sciences, Vol.. 7, NO. 4, 2012, pp.436-446.

[22]. Abdul Arif, Abhishek, K. N. Pandey, "Thermomechanical Modeling for Residual Stresses of Friction Stir Welding of Dissimilar Alloys", International Journal of Engineering Science and Technology, Vol. 5, 2013, pp.11951204.

[23]. N. Rajamanickam, V. Balusamy, P. R. Thyla, G Hari Vignesh, "numerical simulation of thermal history and residual stresses in friction stir welding of Al 2014-T6", journal of scientific \& industrial research, Vol. 68, 2009, pp. 192-198.

[24]. Selvamani S.T, Umanath K, Palanikumar K, "Heat Transfer Analysis during Friction Stir Welding of Al6061-T6 Alloy", International Journal of Engineering Research and Application, Vol. 1, pp. 1453-1460. 